(c) The Authors 2019. This is an Open Access article, distributed under the terms of the Creative Commons Attribution licence (http:// creativecommons.org/licenses/by/4.0/), which permits unrestricted re-use, distribution, and reproduction in any medium, provided the original work is properly cited.

\title{
Postprandial incorporation of EPA and DHA from transgenic Camelina sativa oil into blood lipids is equivalent to that from fish oil in healthy humans
}

\author{
Annette L. West ${ }^{1}$, Elizabeth A. Miles ${ }^{1}$, Karen A. Lillycrop ${ }^{2}$, Lihua Han ${ }^{3}$, Olga Sayanova ${ }^{3}$, \\ Johnathan A. Napier ${ }^{3}$, Philip C. Calder ${ }^{1,4}$ and Graham C. Burdge ${ }^{1 *}$ \\ ${ }^{1}$ School of Human Development and Health, Faculty of Medicine, University of Southampton, Southampton SO16 6YD, UK \\ ${ }^{2}$ Centre for Biological Sciences, Faculty of Natural and Environmental Sciences, University of Southampton, \\ Southampton SO17 1BJ, UK \\ ${ }^{3}$ Department of Plant Sciences, Rothamsted Research, Harpenden AL5 2JQ, UK \\ ${ }^{4}$ NIHR Southampton Biomedical Research Centre, University Hospital Southampton NHS Foundation Trust, \\ University of Southampton, Southampton SO16 6YD, UK
}

(Submitted 2 January 2019 - Final revision received 12 March 2019 - Accepted 27 March 2019 - First published online 3 June 2019)

\section{Abstract}

EPA and DHA are important components of cell membranes. Since humans have limited ability for EPA and DHA synthesis, these must be obtained from the diet, primarily from oily fish. Dietary EPA and DHA intakes are constrained by the size of fish stocks and by food choice. Seed oil from transgenic plants that synthesise EPA and DHA represents a potential alternative source of these fatty acids, but this has not been tested in humans. We hypothesised that incorporation of EPA and DHA into blood lipids from transgenic Camelina sativa seed oil (CSO) is equivalent to that from fish oil. Healthy men and women (18-30 years or 50-65 years) consumed 450 mg EPA + DHA from either CSO or commercial blended fish oil (BFO) in test meals in a double-blind, postprandial cross-over trial. There were no significant differences between test oils or sexes in EPA and DHA incorporation into plasma TAG, phosphatidylcholine or NEFA over $8 \mathrm{~h}$. There were no significant differences between test oils, age groups or sexes in postprandial VLDL, LDL or HDL sizes or concentrations. There were no significant differences between test oils in postprandial plasma TNF $\alpha$, IL 6 or 10, or soluble intercellular cell adhesion molecule-1 concentrations in younger participants. These findings show that incorporation into blood lipids of EPA and DHA consumed as CSO was equivalent to BFO and that such transgenic plant oils are a suitable dietary source of EPA and DHA in humans.

Key words: Transgenic plants: Camelina sativa: DHA: EPA: Postprandial metabolism

Adequate consumption of $n$-3 PUFA derived from marine oily fish, specifically EPA and DHA, is important for development ${ }^{(1)}$ and for maintaining health across the life course ${ }^{(2)}$. Consequently, governments and advisory organisations have published recommendations for EPA and DHA intakes ${ }^{(3)}$. The UK government recommends that all adults should consume at least $450 \mathrm{mg} / \mathrm{d}$ of $\mathrm{EPA}+\mathrm{DHA}^{(4)}$. However, the effectiveness of such recommendations is limited by the dietary choices of the population. In the UK, only $27 \%$ of adult fish consumers eat oily fish $^{(5,6)}$ and most UK adults are considered to consume less than $200 \mathrm{mg} \mathrm{EPA}+$ DHA daily, while intakes in children are about $10 \%$ of those in adults ${ }^{(6)}$. Low oily fish consumption appears to reflect, at least in part, economic cost, perceived unpalatability ${ }^{(6)}$ and adoption of dietary choices that exclude all meat, dairy foods and fish, which are important sources of EPA and DHA in the $\operatorname{diet}^{(7,8)}$. Furthermore, the potential effectiveness of recommendations for EPA + DHA intakes is constrained further by the size of marine sources of these fatty acids. For example, Salem \& Eggersdorfer $^{(9)}$ estimate that if the world population consumed $500 \mathrm{mg} \mathrm{EPA}+$ DHA per day, this could not be met from current marine fish stocks and would incur an annual shortfall of 1.1 million metric tons of EPA + DHA for human consumption.

There is, therefore, a need for alternative sources of EPA and DHA which are sufficiently sustainable and scalable to meet global requirements. EPA and DHA can be synthesised by humans from $\alpha$-linolenic acid which is present in some plant oils ${ }^{(10)}$. However, studies involving stable isotope tracers show that capacity for synthesis of EPA and, especially DHA, is very limited in humans ${ }^{(11)}$, although greater in women than men ${ }^{(12,13)}$. These findings are supported by those from dietary

Abbreviations: BFO, blended fish oil; CM, chylomicron; CSO, Camelina sativa seed oil; FAME, fatty acid methyl esters; iAUC, incremental area under the time $\times$ concentration curve; PC, phosphatidylcholine; sICAM-1, soluble intercellular cell adhesion molecule.

* Corresponding author: G. C. Burdge, email g.c.burdge@soton.ac.uk 
supplementation trials which show that increased $\alpha$-linolenic acid intake can increase EPA, but not DHA, concentration in blood and cell lipids in men and postmenopausal women ${ }^{(10)}$. However, women of reproductive age can maintain higher blood DHA concentration than men ${ }^{(14)}$. Vegetarians and vegans who exclude meat and oily fish from their diet have approximately $50 \%$ lower EPA and DHA status than omnivores ${ }^{(8)}$. Thus, at least in some population groups, $\alpha$-linolenic acid intake does not provide an adequate alternative source of EPA and DHA to consuming these fatty acids preformed ${ }^{(13,15)}$. Krill oil has been proposed as an alternative source of EPA + DHA to oily fish. However, the estimated yield from the total krill catch in 2013 was approximately $0 \cdot 3 \%$ of the global EPA + DHA requirement ${ }^{(16)}$ and claims for greater bioavailability of $n-3$ PUFA from krill oil compared with fish oil appear to be unfounded $^{(17)}$. Algal oils have been proposed as an alternative source of EPA and $\mathrm{DHA}^{(17)}$ and currently account for $2 \%$ of human $\mathrm{EPA}+$ DHA consumption ${ }^{(9)}$. However, the cost of fermentation and refining processes limit the extent to which production of algal sources of EPA and DHA can be scaled to meet demands ${ }^{(9)}$. Overall, there is a need to identify or develop novel sources of EPA and DHA that can replace fish oil to offset the global deficit in EPA and DHA supply.

Vegetable oils derived from genetically modified plants represent one potential means of providing EPA and DHA for the human population which is both sustainable and amenable to changes in scale ${ }^{(18)}$. Such oils may potentially overcome the concerns about the palatability, sustainability and contamination with environmental pollutants that are associated with fish oil ${ }^{(5)}$, and the limited intakes of EPA + DHA by those who exclude oily fish and/or other animal-derived foods from their diet ${ }^{(8)}$. Two strains of the oil seed crop Camelina sativa have been genetically modified to produce oil containing EPA or EPA + $\mathrm{DHA}^{(19,20)}$. These seed oils are potential candidates for replacement of fish oil and oily fish as sources of EPA + DHA in the human diet. However, the EPA and DHA content of the oils differs markedly between the strains. One strain contained $15 \%$ DHA, but only $1.8 \% \mathrm{EPA}^{(20)}$, while the other contained approximately $11 \% \mathrm{EPA}$ and $6 \% \mathrm{DHA}^{(19)}$ which approximates the proportions of these fatty acids in marine fish oil ${ }^{(21)}$. Oil from a strain of $C$. sativa containing $20 \%$ EPA has been shown to be bioavailable and well tolerated in mice ${ }^{(22)}$ and salmon ${ }^{(23)}$. However, humans are unable to convert EPA to $\mathrm{DHA}^{(24)}$ and so oils from transgenic plants that only contain EPA have limited application to meeting demands for both EPA and DHA. Importantly, the bioavailability, tolerance and biological effects of oils containing EPA and DHA from transgenic plants have not yet been tested in humans.

To address this, we tested the hypothesis that EPA and DHA consumed as oil from transgenic $C$. sativa (CSO) are incorporated after a meal into blood lipids at least as well as when consumed as fish oil. In the present study, men and women in two age groups took part in a double-blind, postprandial trial. The study compared the appearance of EPA and DHA in blood lipids over $8 \mathrm{~h}$ following consumption of a single meal containing $450 \mathrm{mg} \mathrm{EPA} \mathrm{+} \mathrm{DHA} \mathrm{provided} \mathrm{as} \mathrm{either} \mathrm{CSO} \mathrm{or} \mathrm{commercial}$ blended fish oil (BFO). Moreover, because we have shown that acute consumption of fish oil can alter the pattern of postprandial changes in lipoprotein size $\mathrm{e}^{(25)}$, we investigated whether the postprandial changes in lipoprotein profiles differed between test meals containing either CSO or BFO. The postprandial period has been associated with an acute increase in specific circulating inflammatory cytokines; namely TNF $\alpha$, IL-6, IL-10 and soluble intercellular cell adhesion molecule (sICAM)-1 which appear to reflect the lipid content of a meal ${ }^{(26)}$. We tested whether the postprandial changes in these cytokines differed between test meals containing CSO or BFO.

\section{Materials and methods}

\section{Preparation of Camelina sativa oil}

Transgenic C. sativa plants producing EPA and DHA in their seed oil were generated according to previously described methods ${ }^{(19)}$. Homozygous $\mathrm{T} 3$ generation transgenic $C$. sativa plants were grown in a controlled environment containment glasshouse under long-day conditions ( $16 \mathrm{~h}$ light and $8 \mathrm{~h}$ dark), $50-60 \%$ relative humidity, with temperature $23^{\circ} \mathrm{C} \mathrm{d} / 18^{\circ} \mathrm{C}$ night, and light intensity of $400 \mu \mathrm{mol} / \mathrm{m}^{2}$ per s. Seeds were harvested and threshed, and the oil was extracted by cold pressing and solvent extraction. The oil was further processed by refining, bleaching and deodorizing (POS Bio-Sciences).

\section{Human postprandial study}

The study was reviewed and approved by the South Central Hampshire B Research Ethics Committee (REC reference 15/SC/ 0627), and the trial is registered at ClinicalTrials.gov (identifier: NCT03477045). All participants gave written informed consent.

The trial had a double-blind cross-over design. Blinding was achieved by labelling of the aliquoted oils by a researcher who was not part of the project team and was maintained until after the statistical analyses were completed. Randomisation of the order of the test meals was assigned using a random number generator (www. Random.org). Participants were healthy men and women aged either 18-30 years or 50-65 years, who did not consume oily fish more than once per week, take fish oil or other dietary supplements, did not smoke tobacco, whose BMI was between 18.5 and $30 \mathrm{~kg} / \mathrm{m}^{2}$, who were not diagnosed as hypertensive and whose non-fasting blood glucose and total cholesterol concentrations were within normal ranges (glucose $<11 \mathrm{mmol} / \mathrm{l}$; cholesterol $\leq 7.5 \mathrm{mmol} / \mathrm{l}$ ). Volunteers were excluded if they did not meet these criteria or if they had diagnosed chronic illness, had been prescribed medicines to lower blood lipids or control hypertension, had gastrointestinal disease, were pregnant or intending to become pregnant within the duration of the trial or who were participating in another trial. The characteristics of the participants in the trial are summarised in Table 1 and their progress through recruitment and participation in the trial is summarised in online Supplementary Fig. S1.

Following health screening, participants attended the Wellcome Trust Clinical Research Facility (University Hospital Trust, Southampton, UK) after an overnight fast (approximately $12 \mathrm{~h}$ ) during which they were only allowed to consume water. A cannula was placed in a forearm vein and a baseline $(10 \mathrm{ml})$ blood sample was collected into an evacuated tube containing 
Table 1. Characteristics of the participants at the start of the study* (Mean values with their standard errors)

\begin{tabular}{|c|c|c|c|c|c|c|c|c|c|}
\hline & \multicolumn{4}{|c|}{ Younger participants } & \multicolumn{4}{|c|}{ Older participants } & \multirow[b]{3}{*}{ ANOVA $(P)$} \\
\hline & \multicolumn{2}{|c|}{ Female (n 10) } & \multicolumn{2}{|c|}{ Male $(n 10)$} & \multicolumn{2}{|c|}{ Female (n 10) } & \multicolumn{2}{|c|}{ Male $(n 6)$} & \\
\hline & Mean & SEM & Mean & SEM & Mean & SEM & Mean & SEM & \\
\hline Age (years) & $25 \cdot 2^{\mathrm{a}}$ & 1 & $25 \cdot 0^{a}$ & 1 & $57^{\mathrm{b}}$ & 1 & $60^{\mathrm{b}}$ & 2 & $<0.0001$ \\
\hline $\mathrm{BMI}\left(\mathrm{kg} / \mathrm{m}^{2}\right)$ & $24 \cdot 3$ & 0.9 & $24 \cdot 4$ & 0.7 & $26 \cdot 4$ & 1 & $24 \cdot 1$ & $1 \cdot 3$ & NS \\
\hline Systolic BP (mmHg) & 112 & 5 & 119 & 3 & 127 & 4 & 121 & 6 & NS \\
\hline Diastolic BP (mmHg) & 69 & 4 & 67 & 3 & 77 & 2 & 75 & 2 & NS \\
\hline Total cholesterol (mmol/l) & $4 \cdot 3^{a}$ & 0.1 & $4 \cdot 2^{a}$ & 0.2 & $5 \cdot 5^{\mathrm{b}}$ & $0 \cdot 2$ & $5 \cdot 1^{a, b}$ & 0.6 & 0.001 \\
\hline Glucose $(\mathrm{mmol} / \mathrm{l})$ & $5 \cdot 2$ & 0.3 & $5 \cdot 6$ & 0.4 & $4 \cdot 7$ & $0 \cdot 2$ & $5 \cdot 3$ & 0.2 & NS \\
\hline Baseline TAG $(\mathrm{mmol} / \mathrm{l})$ & $0.8^{a}$ & 0.07 & $0 \cdot 7^{a, b}$ & 0.07 & $1 \cdot 1^{a, b}$ & 0.18 & $0.8^{\mathrm{b}}$ & 0.08 & 0.04 \\
\hline Baseline PC EPA & $30 \cdot 8^{a}$ & $2 \cdot 2$ & $33 \cdot 2^{\mathrm{a}}$ & 4.5 & $66 \cdot 7^{\mathrm{b}}$ & $7 \cdot 2$ & $55 \cdot 2^{b}$ & $5 \cdot 9$ & $<0.0001$ \\
\hline Baseline PC DHA & $119^{a}$ & $7 \cdot 8$ & $112 \cdot 0^{\mathrm{a}}$ & $6 \cdot 8$ & $154 \cdot 2^{b}$ & 8.5 & $142 \cdot 8^{b}$ & $11 \cdot 3$ & $<0.0001$ \\
\hline Baseline TAG EPA & $4 \cdot 1^{a}$ & 0.5 & $6 \cdot 2^{a}$ & 0.8 & $8 \cdot 7^{b}$ & $1 \cdot 2$ & $12 \cdot 9^{b}$ & 1.6 & $<0.0001$ \\
\hline Baseline TAG DHA & $8 \cdot 3^{a}$ & $1 \cdot 0$ & $9 \cdot 2^{a}$ & 1.4 & $12 \cdot 3^{b}$ & 1.4 & $22 \cdot 1^{b}$ & 3.9 & $<0.0001$ \\
\hline Baseline NEFA EPA & $0.8^{\mathrm{a}}$ & 0.1 & $1 \cdot 0^{\mathrm{a}}$ & 0.2 & $2 \cdot 0^{\mathrm{b}}$ & 0.3 & $1 \cdot 6^{b}$ & 0.2 & $<0.0001$ \\
\hline Baseline NEFA DHA & $3 \cdot 5^{\mathrm{a}}$ & 0.3 & $3 \cdot 0^{\mathrm{a}}$ & 0.2 & $5 \cdot 7^{b}$ & 0.7 & $5 \cdot 0^{b}$ & 0.6 & $<0.0001$ \\
\hline
\end{tabular}

BP, blood pressure; PC, phosphatidylcholine.

a,b Mean values with unlike superscript letters were significantly different $(P<0.05)$.

heparan sulphate anticoagulant. On each of two occasions, at least $14 \mathrm{~d}$ apart, subjects then consumed in random order breakfasts with almost identical nutrient contents and fatty acid compositions which consisted of a milkshake drink, and toast and jam $^{(27)}$ (Table 2). This provided approximately $450 \mathrm{mg}$ $\mathrm{EPA}+\mathrm{DHA}$, equivalent to the daily intake recommended by

Table 2. Compositions of the test oils and test meals*

\begin{tabular}{|c|c|c|c|c|}
\hline & \multicolumn{2}{|c|}{$\begin{array}{c}\text { Test oils } \\
\text { (amount per ml) }\end{array}$} & \multicolumn{2}{|c|}{$\begin{array}{c}\text { Test meal } \\
\text { (amount per meal) }\end{array}$} \\
\hline & BFO & CSO & BFO & $\mathrm{CSO}$ \\
\hline Total protein (g) & & & $12 \cdot 5$ & $12 \cdot 5$ \\
\hline Total carbohydrate $(\mathrm{g})$ & & & $128 \cdot 3$ & $128 \cdot 3$ \\
\hline Total fat (g) & & & $49 \cdot 5$ & $50 \cdot 2$ \\
\hline Total energy (MJ) & & & $43 \cdot 0$ & $43 \cdot 3$ \\
\hline \multicolumn{5}{|l|}{ Fatty acids (mg) } \\
\hline $10: 0$ & ND & ND & 613 & 511 \\
\hline $12: 0$ & ND & ND & 813 & 817 \\
\hline $14: 0$ & 59 & 1 & 2729 & 2638 \\
\hline $16: 0$ & 136 & 67 & 10364 & 10035 \\
\hline $16: 1 n-7$ & 81 & 2 & 641 & 436 \\
\hline $18: 0$ & 28 & 59 & 3984 & 4099 \\
\hline $18: 1 n-9$ & 130 & 47 & 16462 & 16225 \\
\hline $18: 1 n-7$ & 40 & 16 & 541 & 1255 \\
\hline $18: 2 n-6$ & 15 & 172 & 9860 & 10173 \\
\hline $18: 3 n-6$ & 2 & 33 & 37 & 86 \\
\hline $18: 3 n-3$ & 10 & 157 & 2020 & 2052 \\
\hline $20: 0$ & ND & ND & 136 & 209 \\
\hline $20: 1 n-9$ & 63 & 59 & 173 & 220 \\
\hline $20: 2 n-6$ & 2 & 12 & 13 & 28 \\
\hline $20: 3 n-6$ & 1 & 8 & 26 & 46 \\
\hline $20: 4 n-6$ & 9 & 28 & 135 & 196 \\
\hline $20: 4 n-3$ & 68 & 33 & 120 & 113 \\
\hline EPA & 144 & 117 & 243 & 300 \\
\hline $24: 0$ & ND & 6 & 41 & 63 \\
\hline $24: 1 n-9$ & ND & ND & 9 & 13 \\
\hline $22: 5 n-3$ & 18 & 70 & 43 & 131 \\
\hline $\mathrm{DHA}$ & 121 & 93 & 209 & 155 \\
\hline EPA plus DHA & 265 & 210 & 452 & 455 \\
\hline
\end{tabular}

BFO, blended fish oil; CSO, Camelina sativa seed oil; ND, not detected.

* The ingredients used to prepare the test meals were sunflower oil $(13 \mathrm{~g})$, double cream $(42 \mathrm{~g})$, linseed oil $(2.5 \mathrm{~g})$, olive oil $(9 \mathrm{~g})$, bread $(120 \mathrm{~g})$, marmalade $(60 \mathrm{~g})$, Nesquick $(25 \mathrm{~g})$, casein $(1 \mathrm{~g})$, sucrose $(15 \mathrm{~g})$ and test oil BFO $(1.7 \mathrm{ml})$ or CSO $(2.4 \mathrm{ml})$. the UK government ${ }^{(4)}$, either from commercially prepared BFO (452 mg) (Simply Timeless ${ }^{\circledR}$, Omega-3 fish oil plus cod liver oil; Seven Seas) or CSO (455 mg) (Table 2). Venous blood samples were collected at baseline and at 0.5 1 1 1 5, 2, 2·5, 3, 4, 5, 6, 7 and $8 \mathrm{~h}$ after the meal. Participants were allowed to consume water freely throughout, but no further food was provided until the end of the 8-h period. The blood samples were separated into plasma and cell fractions by centrifugation ${ }^{(28)}$, and the plasma was stored at $-80^{\circ} \mathrm{C}$.

\section{Analysis of the fatty acid composition of blood lipids}

The fatty acid composition of plasma phosphatidylcholine (PC), TAG and NEFA was determined by gas chromatography essentially as described ${ }^{(12,28)}$. Briefly, the internal standards dipentadecanoyl PC $(100 \mu \mathrm{g})$, tripentadecanoin $(100 \mu \mathrm{g})$ and heneicosanoic acid $(50 \mu \mathrm{g})$ were added to $0.8 \mathrm{ml}$ plasma and total lipids were then extracted with chloroform-methanol $(2: 1, \mathrm{v} / \mathrm{v})$. The extracted lipids were dried under a stream of nitrogen, dissolved in chloroform and applied under gravity to a $100 \mathrm{mg}$ aminopropyl silica solid phase extraction column (BondElut; Agilent Technologies) and PC, TAG and NEFA eluted under vacuum as described ${ }^{(12)}$. Purified lipid classes were dried under nitrogen and then converted to fatty acid methyl esters (FAME) by reaction with methanol containing $2 \%(\mathrm{v} / \mathrm{v})$ sulphuric acid at $50^{\circ} \mathrm{C}$ for $2 \mathrm{~h}$. The reaction mixture was cooled, neutralised with a solution containing $\mathrm{KHCO}_{3}$ $(0.25 \mathrm{M})$ and $\mathrm{K}_{2} \mathrm{CO}_{3}(0.5 \mathrm{~m})$, and FAME isolated by extraction with hexane. FAME were resolved on a BPX-70 fused silica capillary column $(30 \mathrm{~m} \times 0.25 \mathrm{~mm} \times 25 \mu \mathrm{m})$ using an Agilent 6890 gas chromatograph equipped with flame ionisation detection. Running conditions were as follows: FAME $(1 \mu \mathrm{l})$ were injected into the inlet at $300^{\circ} \mathrm{C}$ in split mode using He as the carrier gas $(1 \mathrm{ml} / \mathrm{min})$. The oven temperature was held at $115^{\circ} \mathrm{C}$ for $2 \mathrm{~min}$ after injection, then increased at $10^{\circ} \mathrm{C} / \mathrm{min}$ to $200^{\circ} \mathrm{C}$ and held at this temperature for $16 \mathrm{~min}$. The oven temperature was then raised at $60^{\circ} \mathrm{C} / \mathrm{min}$ to $240^{\circ} \mathrm{C}$ and held at this temperature for $2 \mathrm{~min}$ to remove any residual material from the column. 
The flame ionisation detector was maintained at $300^{\circ} \mathrm{C}^{(29)}$. Chromatograms were integrated manually using ChemStation software (version B.03.01, Agilent Technologies). Fatty acid concentrations $(\mu \mathrm{g} / \mathrm{ml})$ were calculated by comparison of the peak area of a fatty acid of interest with that of the internal standard and adjusting for the volume of plasma that was extracted ${ }^{(12)}$.

\section{Measurement of lipoprotein concentration and size}

Determination of the concentration and diameter of VLDLchylomicron (VLDL-CM), LDL, IDL and HDL particles was carried out in samples collected at baseline, 1.5 and $6 \mathrm{~h}$ as described previously ${ }^{(25)}$ using NMR spectroscopy by LipoScience Incorporated. This technique is unable to resolve VLDL and $\mathrm{CM}$ particles in postprandial samples, and hence these are reported as a combined VLDL-CM fraction.

\section{Measurement of cytokines in plasma}

The concentrations of sICAM-1, TNF $\alpha$, IL- 6 and IL-10 were measured in plasma samples collected from the younger participants only because of a concern that the lower number of participants in the older male group ( $n$ 6) may not have provided sufficient statistical power to compare any effects of the oils. Retrospective power analysis of the current data confirmed this (a sample size of 10 provided $85 \%$ statistical power to detect a $15 \%$ difference between groups in IL- 6 concentration with $\alpha=0.05$ ). The assays were conducted using human magnetic Luminex multiplex kits (premixed high sensitivity cytokine kit (product number FCSTM09-06) and a premixed multi-analyte kits (product numbers LXSAHM-02 and LXSAHM-05) in accordance with the manufacturer's instructions (R\&D Systems). The plates were read on a Bio-Plex 200 System (Bio-Rad). The assay sensitivity for each analyte was sICAM-1 $87.9 \mathrm{pg} / \mathrm{ml}$, TNF $\alpha 0.54 \mathrm{pg} / \mathrm{ml}$, IL-6 $0.31 \mathrm{pg} /$ $\mathrm{ml}$ and $\mathrm{IL}-100 \cdot 24 \mathrm{pg} / \mathrm{ml}$.

\section{Statistical analysis}

Based on our previous findings ${ }^{(27)}$, ten participants per group were calculated to provide $85 \%$ power for detecting a $10 \%$ difference in peak postprandial concentrations of EPA or DHA in plasma TAG at $\alpha=5 \%$ in a two-tailed analysis. For measurements of change over time, statistical comparisons between groups were by ANOVA with age, sex and test oil as fixed factors and time as a repeated measure with Bonferroni's post boc correction for multiple testing. For single time point and summary measurements, statistical comparisons between groups were by ANOVA with age, sex and test oil as fixed factors with Bonferroni's post hoc correction for multiple testing. Where there were fewer than three groups, pairwise comparisons were by calculation of marginal means. The normality of the distribution of the data sets was tested by analysis of residuals by the Shapiro-Wilk test. Sphericity was not assumed for any outcome and so the GreenhouseGeisser correction was applied to all ANOVA analyses. Data are presented as means with their standard errors and statistical significance was assumed at $P<0 \cdot 05$. Detailed single factor and interaction effects are reported in the online Supplementary Tables S1-S8.

\section{Results}

\section{Participant recruitment and tolerance of the trial}

A total of 179 individuals enquired about the study, of which 112 did not complete the screening questionnaire for undisclosed reasons (online Supplementary Fig. S1). Twenty-three of the remaining sixty-seven volunteers who were assessed for eligibility against the study inclusion criteria were either found to be ineligible or decided not to participate. Eight of the forty-four of remaining volunteers who gave written consent to take part in the study withdrew before randomisation, primarily because of the time commitment required for the postprandial studies. This was also the main reason why it was not possible to recruit all ten participants in the older male group. The remaining thirtysix participants completed both postprandial sessions.

There were two cases of minor upper respiratory tract infections (a cold and tonsillitis) out of the seventy-two postprandial sessions. One participant experienced a minor nose bleed some hours after one postprandial session, but disclosed that they had a pre-existing non-clinical tendency towards this. One participant developed pyelonephritis between postprandial sessions which was fully resolved. Three participants reported headaches during both postprandial sessions. None of these minor illnesses was associated with consuming a specific oil and all were considered unlikely to be caused by consuming a particular test oil. No major adverse symptoms or health effects were reported by the participants. The four groups of participants did not differ significantly in BMI, systolic or diastolic blood pressure or random glucose concentration (Table 1). Total cholesterol concentration did not differ significantly between younger males and females, and older males, but was significantly higher in the older female group compared with the other three groups (Table 1). EPA and DHA concentrations at baseline in plasma TAG, PC and NEFA were significantly greater in older compared with younger subjects irrespective of sex (Table 1). The rank order of baseline EPA and DHA concentrations was plasma PC $>$ TAG $>$ NEFA (Table 1 ).

\section{The effect of the test oils on postprandial plasma EPA and DHA concentrations in TAG, phosphatidylcholine and NEFA}

EPA and DHA concentrations in plasma TAG changed (both $P<0.0001)$ as expected during the postprandial period in all participant groups (Fig. 1, the results of statistical analyses are shown in online Supplementary Table S1). There were no significant single factor or interaction effects of the type of oil, or the sex or age of the participants on the postprandial changes in EPA and DHA concentration (Fig. 1, online Supplementary Table S1). The postprandial changes in EPA and DHA concentrations and in the combined concentrations of EPA + DHA in plasma TAG were summarised by calculating the incremental area under the time $\times$ concentration curve (iAUC) (Table 3 ). There were no significant single-factor effects of the type of oil or the sex of the participants on the iAUC of EPA concentration in plasma TAG, however there was a significant $(P<0.0001)$ effect of age (Table 3 , the results of statistical analyses are shown in online Supplementary Table S2). Calculation of the marginal 
(a)

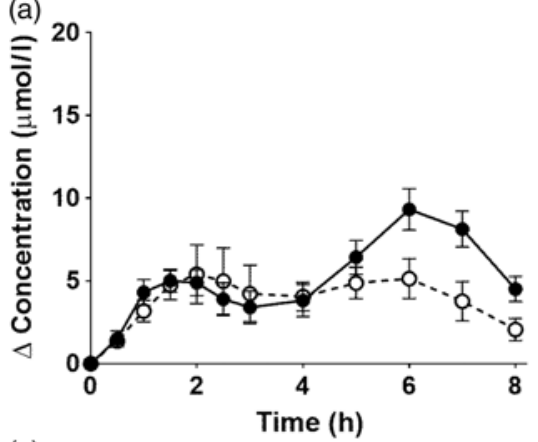

(c)
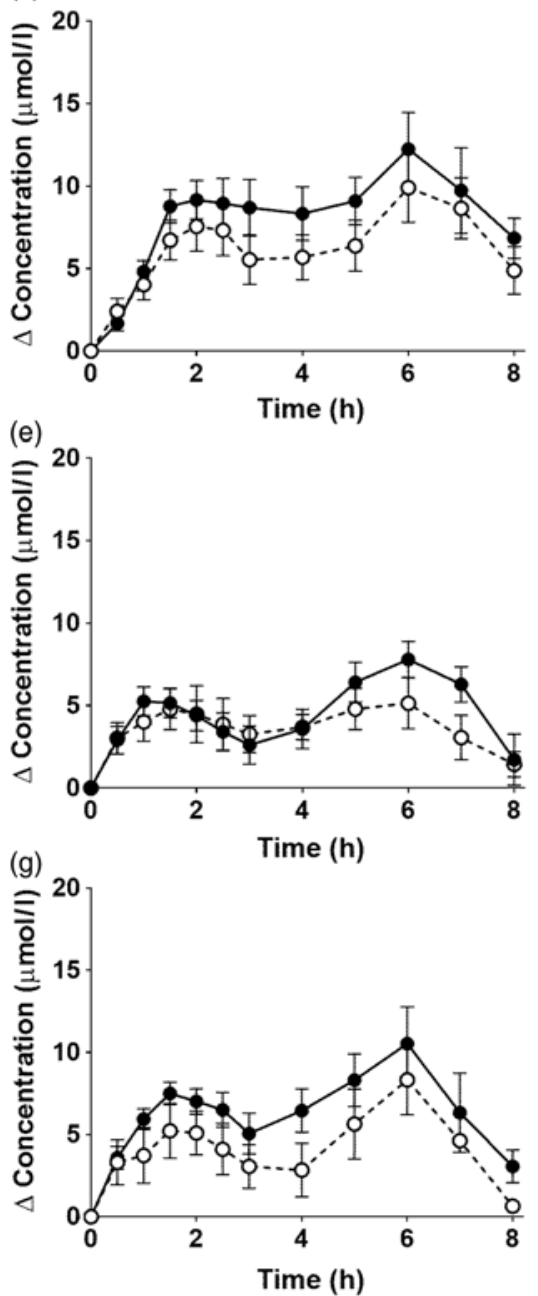

(b)

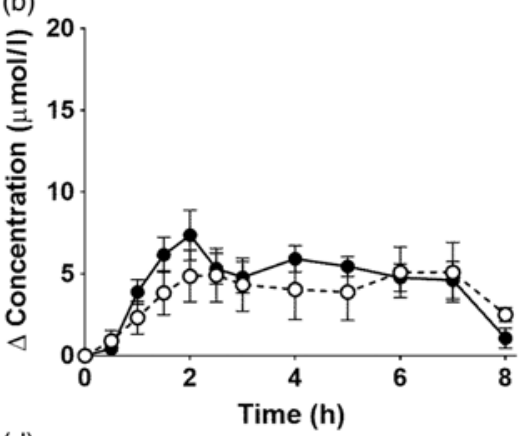

(d)
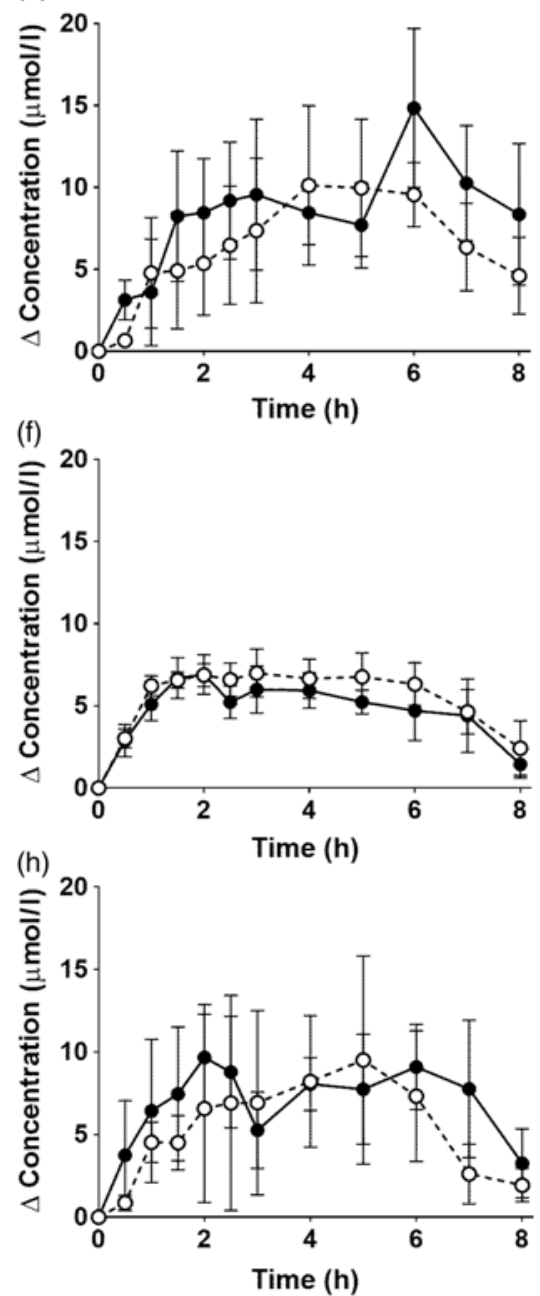

Fig. 1. Postprandial incorporation of EPA and DHA into plasma TAG. Values are changes in concentration from baseline of EPA (a-d) and DHA (e-h) in plasma TAG following consumption of test meals containing either Camelina sativa seed oil (-•-) or blended fish oil (-O-) ( $n$ 10/group). (a) and (e), younger females ( $n$ 10); (b) and (f), younger males ( $n$ 10); (c) and (g), older females ( $n$ 10); (d) and (h), older males ( $n 6)$. Data are means, with standard errors represented by vertical bars. The results of statistical analysis by ANOVA with Bonferroni's post hoc correction are described in online Supplementary Table S1.

means for age showed that the TAG EPA iAUC was approximately $60 \%$ greater $(P<0.0001)$ in older participants $(60.9$ (SEM 4.6) $\mu \mathrm{mol} / \mathrm{l}$ over $8 \mathrm{~h}$ ) compared with younger participants (38.6 (sem 3.9) $\mu \mathrm{mol} / \mathrm{l}$ over $8 \mathrm{~h}$ ). There were no significant single-factor effects of the type of oil or the sex of the participants or significant interaction effects of age, sex and type of oil on the iAUC of DHA in plasma TAG (Table 3, online Supplementary Table S2). However, there was a significant single-factor effect of age on the iAUC of DHA concentration in plasma TAG
$(P=0.03)$ (online Supplementary Table S2). Calculation of the marginal means for age showed that the TAG DHA iAUC was approximately $40 \%$ greater $(P=0.03)$ in older participants (54.9 (sem 5.3) $\mu \mathrm{mol} / \mathrm{l}$ over $8 \mathrm{~h}$ ) compared with younger participants (39.1 (sem 4.6) $\mu \mathrm{mol} / \mathrm{l}$ over $8 \mathrm{~h}$ ). There was no significant difference between test oils in the iAUC for EPA + DHA in plasma TAG (Table 3, online Supplementary Table S2). There were no significant differences between sexes in the iAUC for $\mathrm{EPA}+\mathrm{DHA}$ in plasma TAG, while the iAUC for 
Table 3. Incremental area under the time $\times$ concentration curves (iAUC) of the incorporation of EPA and DHA into plasma TAG, phosphatidylcholine (PC) and NEFA*

(Mean values with their standard errors)

\begin{tabular}{|c|c|c|c|c|c|c|c|c|c|c|c|c|c|c|c|c|}
\hline \multirow{5}{*}{ Test oil... } & \multicolumn{16}{|c|}{$\mathrm{iAUC}(\mu \mathrm{mol} / \mathrm{l} \times \mathrm{h})$} \\
\hline & \multicolumn{8}{|c|}{ Younger participants } & \multicolumn{8}{|c|}{ Older participants } \\
\hline & \multicolumn{4}{|c|}{ Female $(n 10)$} & \multicolumn{4}{|c|}{ Male $(n 10)$} & \multicolumn{4}{|c|}{ Female $(n 10)$} & \multicolumn{4}{|c|}{ Male $(n 6)$} \\
\hline & \multicolumn{2}{|c|}{ CsO } & \multicolumn{2}{|c|}{ BFO } & \multicolumn{2}{|c|}{ CsO } & \multicolumn{2}{|c|}{ BFO } & \multicolumn{2}{|c|}{ CsO } & \multicolumn{2}{|c|}{ BFO } & \multicolumn{2}{|c|}{ cso } & \multicolumn{2}{|c|}{ BFO } \\
\hline & Mean & SEM & Mean & SEM & Mean & SEM & Mean & SEM & Mean & SEM & Mean & SEM & Mean & SEM & Mean & SEM \\
\hline TAG EPA & $42 \cdot 7$ & $6 \cdot 3$ & 31.4 & 4.3 & 40.3 & $9 \cdot 2$ & 39.7 & 4.0 & $60 \cdot 5$ & $6 \cdot 3$ & $52 \cdot 1$ & $7 \cdot 6$ & $70 \cdot 7$ & 14.5 & $60 \cdot 1$ & $19 \cdot 1$ \\
\hline TAG DHA & 38.6 & $38 \cdot 6$ & $31 \cdot 7$ & $6 \cdot 7$ & 41.4 & 4.7 & 44.6 & $7 \cdot 2$ & $52 \cdot 0$ & $7 \cdot 1$ & $43 \cdot 0$ & 8.5 & $62 \cdot 0$ & $16 \cdot 2$ & $62 \cdot 6$ & $24 \cdot 6$ \\
\hline TAG EPA + DHA & 81.4 & 13.9 & 63.1 & $10 \cdot 8$ & 81.7 & $12 \cdot 1$ & 84.4 & 7.4 & 112.5 & $12 \cdot 2$ & $95 \cdot 2$ & $14 \cdot 8$ & $132 \cdot 7$ & $21 \cdot 8$ & $122 \cdot 8$ & $43 \cdot 3$ \\
\hline PC EPA & $66 \cdot 1$ & $12 \cdot 7$ & 65.5 & 9.5 & $48 \cdot 1$ & $10 \cdot 7$ & $60 \cdot 0$ & $10 \cdot 1$ & $92 \cdot 1$ & $15 \cdot 9$ & 94.4 & $24 \cdot 1$ & $100 \cdot 7$ & $25 \cdot 5$ & 98.8 & $45 \cdot 3$ \\
\hline PC DHA & $105 \cdot 6$ & 19.8 & 94.3 & $21 \cdot 7$ & $75 \cdot 9$ & $20 \cdot 6$ & $107 \cdot 8$ & $22 \cdot 2$ & $150 \cdot 4$ & 23.3 & $108 \cdot 9$ & 28.0 & 213.7 & $26 \cdot 8$ & 160.5 & 71.4 \\
\hline $\mathrm{PC} E P A+D H A$ & $171 \cdot 8$ & 31.9 & $159 \cdot 8$ & $25 \cdot 1$ & 123.9 & $30 \cdot 1$ & 167.8 & $30 \cdot 3$ & 242.5 & 34.7 & $203 \cdot 4$ & $42 \cdot 4$ & 314.4 & 65.4 & $259 \cdot 3$ & 114.9 \\
\hline NEFA EPA & $18 \cdot 2$ & 0.7 & 17 & 0.9 & $18 \cdot 1$ & 0.5 & $18 \cdot 1$ & 0.5 & $21 \cdot 7$ & 1.4 & $14 \cdot 4$ & $2 \cdot 1$ & $17 \cdot 8$ & $2 \cdot 2$ & $20 \cdot 0$ & $1 \cdot 6$ \\
\hline NEFA DHA & $68 \cdot 1$ & $3 \cdot 0$ & 68.0 & $2 \cdot 2$ & 68.0 & 2.9 & 69.2 & 1.5 & $70 \cdot 6$ & $2 \cdot 7$ & $56 \cdot 2$ & 5.6 & $66 \cdot 9$ & 1.4 & $67 \cdot 4$ & 3.8 \\
\hline NEFA EPA + DHA & $86 \cdot 4$ & 3.3 & $85 \cdot 0$ & $2 \cdot 6$ & $86 \cdot 1$ & $2 \cdot 2$ & $87 \cdot 3$ & $1 \cdot 8$ & $92 \cdot 2$ & 3.5 & $70 \cdot 7$ & $7 \cdot 4$ & $84 \cdot 6$ & $2 \cdot 9$ & $87 \cdot 4$ & $5 \cdot 2$ \\
\hline
\end{tabular}

CSO, Camelina sativa seed oil; BFO, blended fish oil.

* Values are concentrations of EPA and DHA in PC, TAG and NEFA over $8 \mathrm{~h}$ summarised as iAUC. The results of analysis by ANOVA with type of oil, sex and age as fixed factors and post hoc correction by Bonferroni's method are described in online Supplementary Tables S2, S4 and S6.

EPA + DHA was greater in older compared with younger participants (Table 3, online Supplementary Table S2). These data are exemplified in the time versus concentration graph for $\mathrm{EPA}+\mathrm{DHA}$ in plasma TAG (online Supplementary Fig. S2, the results of statistical analyses are shown in online Supplementary Table S1).

EPA and DHA concentrations in plasma PC changed as expected during the postprandial period (Fig. 2, online Supplementary Table S3; both $P<0 \cdot 0001$ ). There were no significant interaction effects between time after the meal and the type of oil, and the sex or age of the participants on postprandial EPA or DNA concentrations (Fig. 2, online Supplementary Table S3).

There were no significant single-factor effects of the type of oil or the sex of the participants on the iAUC of EPA or DHA in plasma PC (Table 3, online Supplementary Table S4). There was a significant single factor significant effect of age on the iAUC of EPA $(P=0 \cdot 01)$ and DHA $(P=0.005)$ in plasma PC (Table 3, online Supplementary Table S4). There were no significant interaction effects on plasma PC EPA or DHA iAUC (online Supplementary Table S4). Calculation of marginal means for age showed that the iAUC for EPA in plasma PC was 60 $\%$ greater in older participants (11 (sem 1$) \mu \mathrm{mol} / \mathrm{l}$ over $8 \mathrm{~h}$ ) compared with younger participants ( 7 ( $\operatorname{sem} 1) \mu \mathrm{mol} / \mathrm{l}$ over $8 \mathrm{~h}$ ). The marginal means for age also showed that the iAUC for DHA in plasma PC was $65 \%$ greater in older participants (158 (SEM 16) $\mu \mathrm{mol} / \mathrm{l}$ over $8 \mathrm{~h}$ ) compared with younger participants (96 (SEM 14) $\mu \mathrm{mol} / \mathrm{l}$ over $8 \mathrm{~h}$ ). There was no significant difference between test oils in the iAUC for EPA + DHA in plasma PC (Table 3, online Supplementary Table S2). There were no significant differences between sexes in the iAUC for EPA + DHA in plasma TAG, while the iAUC for EPA + DHA was greater in older compared with younger participants (Table 3, online Supplementary Table S2).

There was a significant effect of time on the concentrations of EPA and DHA in plasma NEFA (Fig. 3, online Supplementary Table S5; both $P<0 \cdot 0001)$. However, there were no significant single-factor effects of the type of oil, nor the sex or age of the participants on the concentrations of EPA and DHA in plasma NEFA during the postprandial period (online Supplementary Table S5). There were no significant single-factor effects of the type of oil, nor the sex or age of the participants, nor any interaction effects between these factors on the iAUC of EPA or DHA concentrations in plasma NEFA (Table 3, online Supplementary Table S6). There was no significant difference between test oils in the iAUC for EPA + DHA in plasma NEFA (Table 3, online Supplementary Table S2). There were no significant differences between sexes in the iAUC for EPA + DHA in plasma TAG, while the iAUC for EPA + DHA was greater in older compared with younger participants (Table 3, online Supplementary Table S2).

\section{The effect of the test oils on postprandial lipoprotein concentrations and diameters}

VLDL-CM concentration changed significantly after consuming the test meals (both $P<0.0001$ ) such that VLDL-CM concentration was greater at $1.5 \mathrm{~h}$ than at baseline (Table 4 , online Supplementary Table S7). The change in VLDL-CM concentration was greater in older compared with younger participants (time $\times$ age $P=0.02)$ related to sex $(P<0.01)$, but not the type of oil consumed (time $\times$ oil $\times$ age $\times \operatorname{sex}, P=0.9$ ) (Table 4 , online Supplementary Table S7).

LDL concentration changed significantly after the test meals (both $P<0.0001$ ) such that LDL concentration was greater at $1.5 \mathrm{~h}$ and at $6 \mathrm{~h}$ compared with baseline. However, there were no significant effects of the type of oil consumed, nor of the age or sex of the participants on the postprandial changes in LDL concentration (Table 4, online Supplementary Table S7).

There was a significant effect of time after the test meals (both $P<0.0001$ ) on HDL concentration such that the levels at 1.5 and $6 \mathrm{~h}$ were greater than at baseline (Table 4 , online Supplementary Table S7). There was no significant effect of the type of oil consumed, nor of the age or sex of the participants HDL concentration (Table 4, online Supplementary Table S7). 

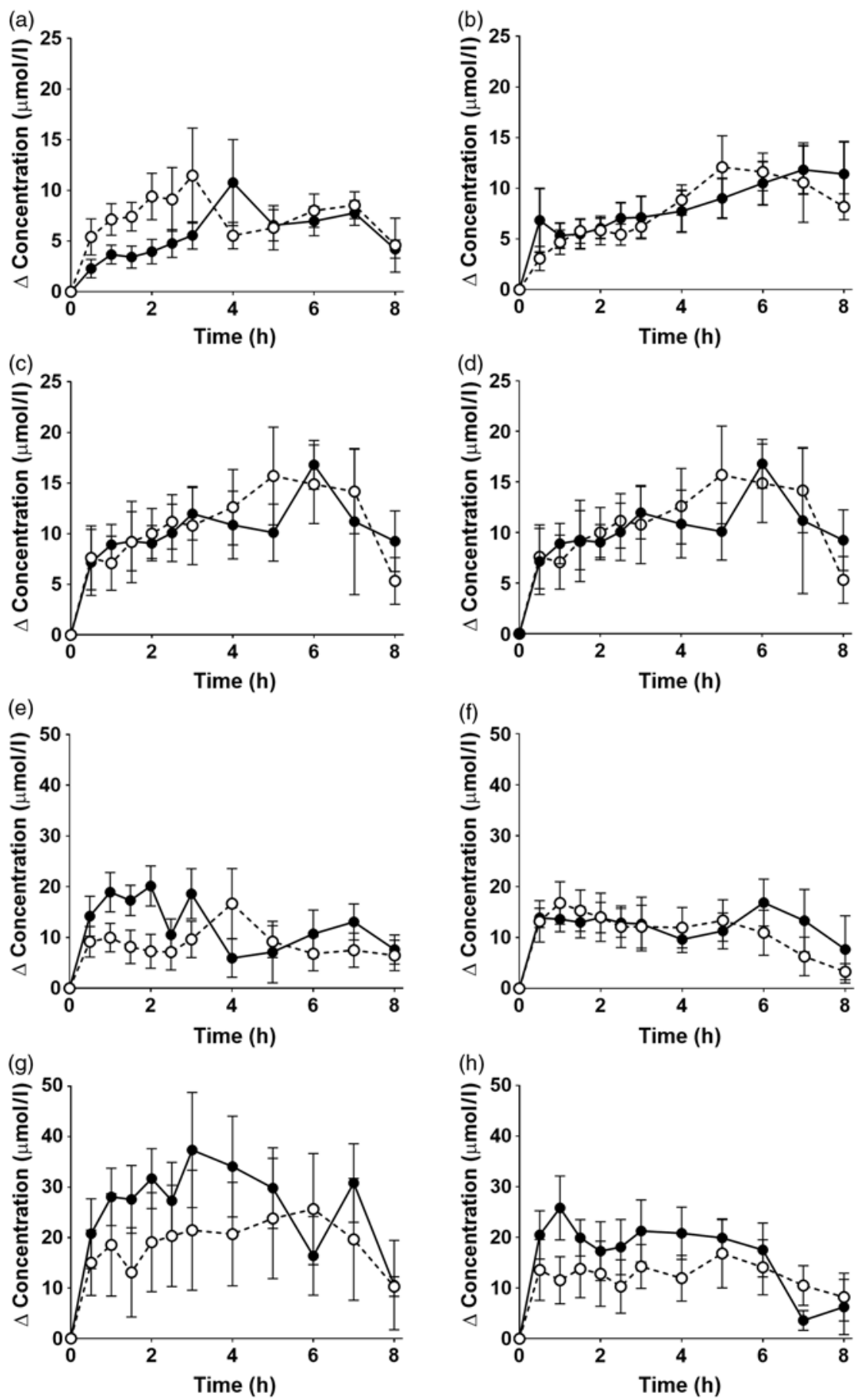

Fig. 2. Postprandial incorporation of EPA and DHA into plasma phosphatidylcholine. Values are changes in concentration from baseline of EPA (a-d) and DHA (e-h) in plasma phosphatidylcholine following consumption of test meals containing either Camelina sativa seed oil (---) or blended fish oil (-O-). (a) and (e), younger females $(n 10)$; (b) and (f), younger males ( $n 10)$; (c) and (g), older females $(n 10)$; $(d)$ and (h), older males $(n 6)$. Data are means, with standard errors represented by vertical bars. The results of statistical analysis by ANOVA with Bonferroni's post hoc correction are described in online Supplementary Table S3.

There was a significant effect of time after the meal $(P=0 \cdot 001)$ on VLDL-CM $(P=0 \cdot 001)$, LDL $(P<0 \cdot 0001)$ and HDL $(P<0 \cdot 0001)$ diameter (Table 4, online Supplementary Table S7). However, there was no significant effect the type of oil, nor of the type of oil nor the age and sex of the participants on postprandial VLDL-CM, LDL or HDL diameter (Table 4, online Supplementary Table S7).
The effect of the test oils on the postprandial inflammatory response

There were significant postprandial changes in the concentrations of TNF $\alpha$, IL- 6 and IL-10 (time $\times$ concentration all $P<0.0001$ ), but not in the level of sICAM-1 (Fig. 4, online Supplementary Table S8). There were no significant effects of 

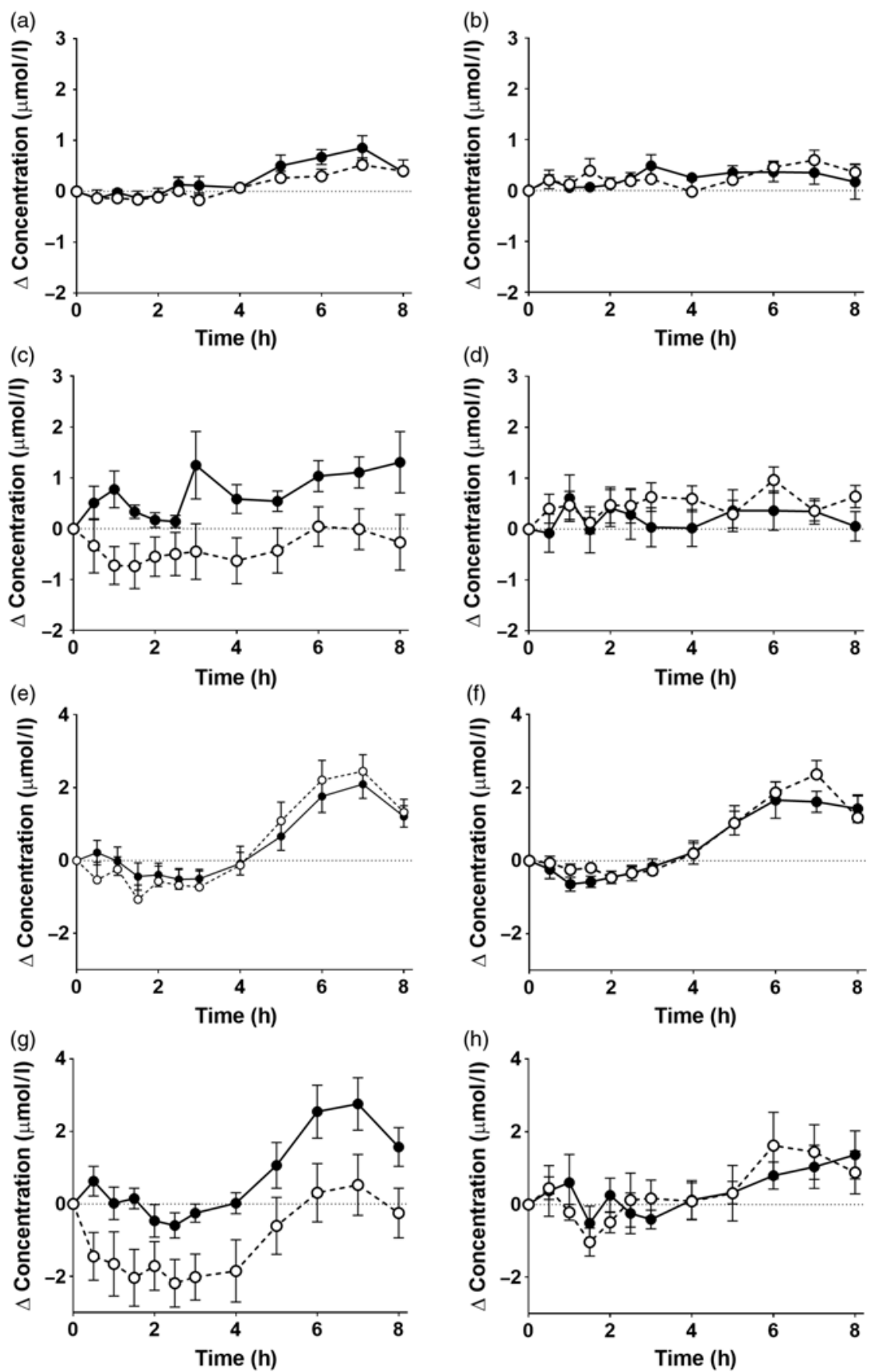

Fig. 3. Postprandial incorporation of EPA and DHA into plasma NEFA. Values are changes in concentration from baseline of EPA (a-d) and DHA (e-h) in plasma NEFA following consumption of test meals containing either Camelina sativa seed oil (---) or blended fish oil (-O-). (a) and (e), younger females ( $n 10)$; (b) and (f), younger males $(n 10)$; (c) and (g), older females ( $n 10)$; (d) and (h), older male ( $n 6)$. Data are means, with standard errors represented by vertical bars. The results of statistical analysis by ANOVA with Bonferroni's post hoc correction are described in online Supplementary Table S5.

the type of oil nor of the sex of the participants in the postprandial changes in TNF $\alpha$, IL- 6 and IL-10 or SICAM-1 concentrations (online Supplementary Table S8).

\section{Discussion}

The findings of this study showed that EPA and DHA, when measured either as individual fatty acids or when combined, have equivalent incorporation into blood lipids when consumed as $\mathrm{CSO}$ as when consumed as BFO. Although the amount of EPA in the CSO test meal was greater than in the BFO meal, and conversely for DHA, the magnitude of this difference was not sufficiently great to result in statistically differences between oils in the postprandial incorporation of these fatty acids into plasma lipids. EPA and DHA were incorporated into plasma TAG and PC during the postprandial period, which primarily represents 
Table 4. Lipoprotein concentrations and diameters

(Mean values with their standard errors)

\begin{tabular}{|c|c|c|c|c|c|c|c|c|c|c|c|c|c|c|c|c|}
\hline \multirow{4}{*}{ Test oil... } & \multicolumn{8}{|c|}{ Younger participants } & \multicolumn{8}{|c|}{ Older participants } \\
\hline & \multicolumn{4}{|c|}{ Male $(n 10)$} & \multicolumn{4}{|c|}{ Female $(n 10)$} & \multicolumn{4}{|c|}{ Male $(n 6)$} & \multicolumn{4}{|c|}{ Females $(n 10)$} \\
\hline & \multicolumn{2}{|c|}{ cso } & \multicolumn{2}{|c|}{ BFO } & \multicolumn{2}{|c|}{$\mathrm{CSO}$} & \multicolumn{2}{|c|}{ BFO } & \multicolumn{2}{|c|}{$\mathrm{CsO}$} & \multicolumn{2}{|c|}{ BFO } & \multicolumn{2}{|c|}{$\mathrm{CsO}$} & \multicolumn{2}{|c|}{ BFO } \\
\hline & Mean & SEM & Mean & SEM & Mean & SEM & Mean & SEM & Mean & SEM & Mean & SEM & Mean & SEM & Mean & SEM \\
\hline \multicolumn{17}{|l|}{ Concentrations (nmol/l) } \\
\hline VLDL-CM $0 \mathrm{~h}$ & $36 \cdot 9$ & 3.4 & $34 \cdot 1$ & 3.8 & $35 \cdot 2$ & 4.8 & 25.4 & 2.9 & 34 & 3 & 34.3 & $5 \cdot 6$ & 33.9 & 4.0 & $30 \cdot 7$ & 3.1 \\
\hline VLDL-CM $1.5 \mathrm{~h}$ & $52 \cdot 3$ & $4 \cdot 3$ & $45 \cdot 1$ & 5.5 & 38.9 & 3.6 & $35 \cdot 7$ & $3 \cdot 2$ & 49 & 6 & 44.0 & 4.5 & $40 \cdot 7$ & 4.6 & $45 \cdot 4$ & 5.4 \\
\hline VLDL-CM $6 \mathrm{~h}$ & $35 \cdot 5$ & $6 \cdot 2$ & 31.4 & $4 \cdot 2$ & $34 \cdot 1$ & 3.5 & $35 \cdot 4$ & $5 \cdot 1$ & 50 & 8 & $48 \cdot 6$ & $5 \cdot 4$ & $36 \cdot 9$ & 5.5 & $40 \cdot 8$ & 5.5 \\
\hline LDL $0 \mathrm{~h}$ & 738 & 78 & 707 & 61 & 757 & 84 & 697 & 81 & 969 & 226 & 880 & 177 & 880 & 84 & 836 & 48 \\
\hline LDL $1.5 \mathrm{~h}$ & 826 & 78 & 837 & 81 & 888 & 90 & 831 & 71 & 1080 & 224 & 1062 & 231 & 989 & 88 & 993 & 78 \\
\hline LDL $6 \mathrm{~h}$ & 817 & 78 & 839 & 70 & 854 & 66 & 802 & 69 & 1134 & 228 & 1075 & 230 & 983 & 86 & 974 & 76 \\
\hline $\mathrm{HDL} 0 \mathrm{~h}(\mu \mathrm{mol} / \mathrm{l})$ & 26 & 1 & 26 & 2 & 27 & 1 & 26 & 1 & 27 & 1 & 28 & 2 & 30 & 2 & 28 & 1 \\
\hline $\mathrm{HDL} 1.5 \mathrm{~h}(\mu \mathrm{mol} / \mathrm{l})$ & 31 & 2 & 32 & 2 & 33 & 1 & 32 & 1 & 34 & 2 & 34 & 2 & 34 & 2 & 33 & 2 \\
\hline $\mathrm{HDL} 6 \mathrm{~h}(\mu \mathrm{mol} / \mathrm{l})$ & 30 & 1 & 31 & 2 & 31 & 1 & 31 & 1 & 34 & 2 & 34 & 2 & 33 & 2 & 33 & 1 \\
\hline \multicolumn{17}{|l|}{ Diameter (nm) } \\
\hline VLDL-CM $0 \mathrm{~h}$ & 51 & 3 & 52 & 2 & 49 & 1 & 53 & 2 & 60 & 4 & 54 & 2 & 52 & 2 & $49 \cdot 4$ & 2 \\
\hline VLDL-CM $1.5 \mathrm{~h}$ & 50 & 2 & 52 & 2 & 53 & 2 & 51 & 3 & 56 & 3 & 53 & 3 & 52 & 2 & 47 & 1 \\
\hline VLDL-CM 6 h & 47 & 2 & 49 & 1 & 49 & 1 & 46 & 2 & 55 & 2 & 55 & 4 & 49 & 1 & 48 & 2 \\
\hline LDL $0 \mathrm{~h}$ & $20 \cdot 5$ & 0.2 & $20 \cdot 7$ & 0.2 & $20 \cdot 6$ & 0.2 & $20 \cdot 7$ & $0 \cdot 2$ & $20 \cdot 6$ & 0.2 & $20 \cdot 6$ & 0.2 & $21 \cdot 3$ & $0 \cdot 1$ & $21 \cdot 2$ & 0.1 \\
\hline LDL $1.5 \mathrm{~h}$ & $20 \cdot 9$ & 0.1 & $20 \cdot 7$ & 0.1 & $21 \cdot 0$ & 0.1 & $20 \cdot 8$ & $0 \cdot 2$ & $20 \cdot 7$ & 0.2 & $20 \cdot 7$ & $0 \cdot 2$ & 21.4 & $0 \cdot 1$ & $21 \cdot 3$ & 0.1 \\
\hline LDL $6 \mathrm{~h}$ & $21 \cdot 1$ & 0.1 & 0.1 & 0.1 & $21 \cdot 1$ & 0.1 & 21.0 & 0.2 & 20.7 & 0.1 & $20 \cdot 9$ & 0.1 & 21.4 & 0.1 & 21.4 & 0.2 \\
\hline $\mathrm{HDL} 0 \mathrm{~h}$ & 9.5 & 0.1 & 9.5 & 0.1 & 9.7 & 0.1 & 9.9 & 0.1 & 9.6 & 0.3 & $9 \cdot 6$ & 0.3 & $10 \cdot 1$ & 0.1 & $10 \cdot 6$ & 0.1 \\
\hline $\mathrm{HDL} 1.5 \mathrm{~h}$ & 9.4 & 0.1 & 9.5 & 0.1 & 9.7 & 0.1 & 9.8 & 0.1 & 9.6 & 0.3 & 9.5 & 0.3 & $10 \cdot 1$ & 0.1 & $10 \cdot 0$ & 0.1 \\
\hline HDL $6 \mathrm{~h}$ & $9 \cdot 6$ & 0.1 & $9 \cdot 6$ & 0.1 & 9.9 & 0.1 & $10 \cdot 0$ & 0.1 & $9 \cdot 6$ & 0.2 & $9 \cdot 8$ & 0.2 & $10 \cdot 2$ & $0 \cdot 1$ & $10 \cdot 1$ & 0.1 \\
\hline
\end{tabular}

CSO, Camelina sativa seed oil; BFO, blended fish oil; CM, chylomicron.

* Values are concentrations and diameters of individual lipoprotein classes at baseline, and at 1.5 and $6 \mathrm{~h}$ after consuming a test meal containing either the CSO or BFO. The results of ANOVA with type of oil, sex and age as fixed factors, and time as a repeated measure with post hoc correction by Bonferroni's method are provided in online Supplementary Table S7.

secretion into the circulation of fatty acids derived from a meal. The baseline concentrations of EPA and DHA and the iAUC for postprandial EPA and DHA concentrations in PC were consistently greater than in TAG (iAUC EPA, approximately 1.6-fold; iAUC DHA, approximately 3-fold). This is consistent with previous reports that showed EPA and DHA incorporation into plasma PC was greater than TAG after fasting and during the postprandial period ${ }^{(28,30,31)}$ and suggests that EPA and DHA are preferentially incorporated into PC during chylomicron and VLDL assembly. One alternative possibility is that EPA and DHA esterified to TAG may be turned over faster than when esterified to PC. Nevertheless, there was no significant effect of the type of oil consumed on incorporation of EPA and DHA in plasma TAG or PC. In fish oil, almost all of the DHA and $44 \%$ of EPA are esterified at the $s n-2$ position $^{(32)}$. By contrast, in CSO, EPA and DHA are esterified predominately at the $s n-1$ or 3 positions ( $s n-1$ plus $s n-3: s n-2$; EPA 3:2, DHA 3:1) ${ }^{(19)}$. Fatty acids that are esterified at the $s n-1$ or -3 positions can have greater incorporation into plasma TAG, than those at the $s n-2$ position due to the lower accessibility of the $s n-2$ position to pancreatic and lipoprotein lipases ${ }^{(33,34)}$. Thus, it may be anticipated that EPA and DHA from CSO may be greater than from BFO. Moreover, the BFO contained substantially more $14: 0$ and 18:0, and less $18: 2 n-6$ and less $18: 3 n-3$ than the CSO. Such differences in the composition of the TAG between oils could alter the access of lipases to the glycerol to EPA or DHA bonds. However, based on the incorporation of EPA and DHA into plasma TAG and PC, any differences in the composition and structure of the test oils did not significantly alter their digestion, absorption or transport in blood of EPA and DHA.
Incorporation of EPA and DHA into the plasma NEFA pool during the postprandial period reflects incomplete entrapment of fatty acids released by lipoprotein lipase activity, particularly that associated with adipose tissue ${ }^{(35)}$. Incorporation of DHA into the NEFA pool during the postprandial period has been shown to be greater than $\mathrm{EPA}^{(36,37)}$, which has been suggested to explain the higher incorporation of DHA than EPA into VLDL TAG after a meal ${ }^{(37)}$. The present findings are consistent with the observation that DHA is incorporated preferentially into the plasma NEFA pool after a meal, but there appeared to be no selective incorporation of EPA or DHA into plasma TAG, which may be because chylomicrons and VLDL particles were not analysed separately in the present study. There was no significant difference between the test oils in the incorporation of EPA and DHA into plasma NEFA. If it assumed that this reflects the product of lipoprotein lipase activity and the efficiency of cellular entrapment, then these findings suggest equivalent uptake and partitioning of EPA and DHA by peripheral tissues when consumed as CSO or $\mathrm{BFO}$.

The participants showed similar tolerance of the test meals irrespective of whether they contained CSO or BFO. Moreover, few health events were noted, none of which was likely to be related to participation in the study per se. We measured two outcomes that, if altered by the test meals could indicate an adverse effect on health. Consumption of a meal containing fish oil can reduce VLDL particle size and increase VLDL concentration during the postprandial period ${ }^{(25)}$. Our findings show expected changes in VLDL-CM, LDL and HDL concentrations and sizes after the test meals, but there were no significant differences between the test oils. This suggests that the effect 

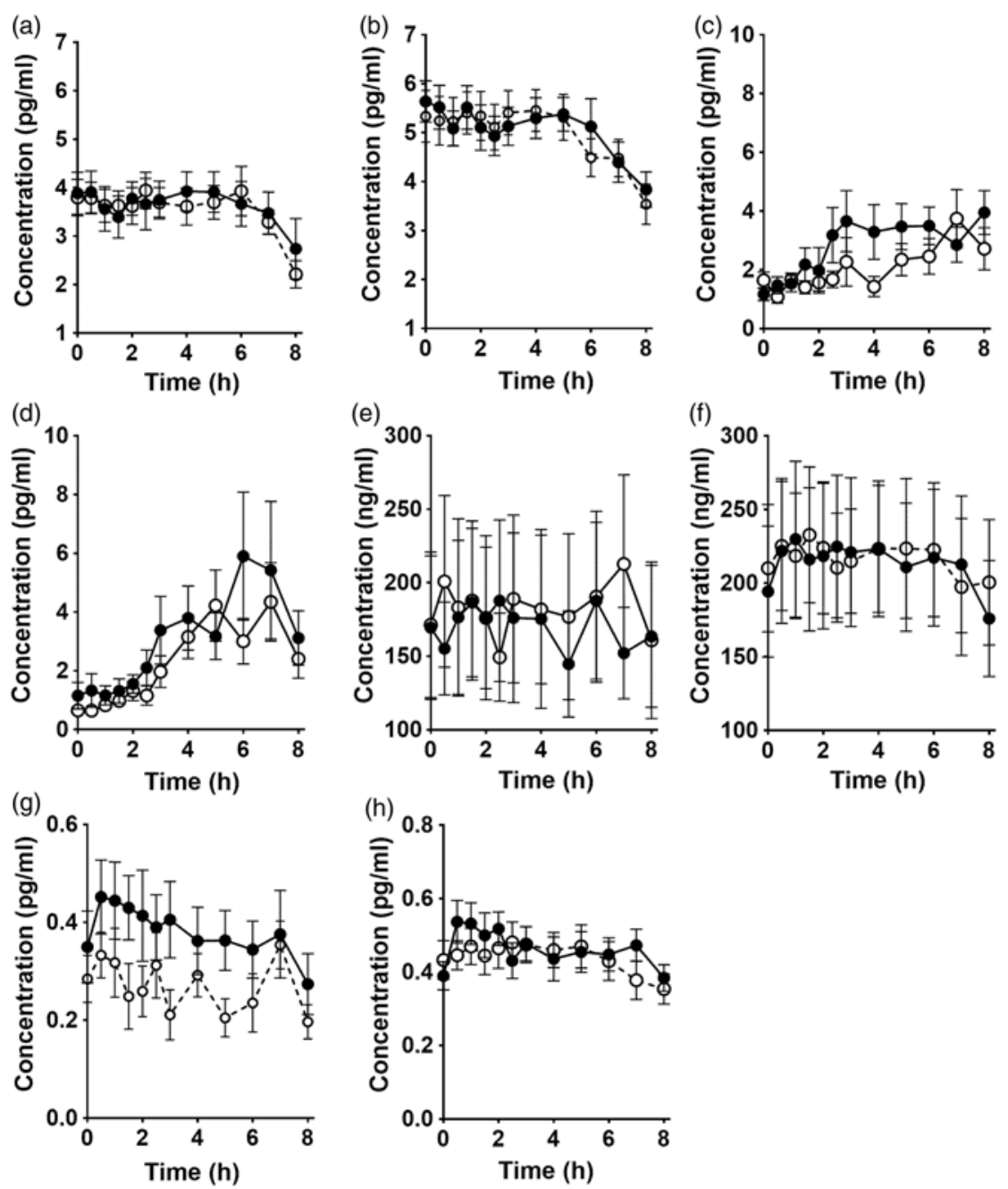

Fig. 4. Concentrations of $(a, b) T N F \alpha$, (c, d) IL-6, (e, f) soluble intercellular adhesion molecule-1 and (g, h) IL-10 in plasma following consumption of test meals containing either Camelina sativa seed oil (--) or blended fish oil (-o-) from younger male (b, d, f, h) or female (a, c, e, g) participants aged 18-35 years ( $n$ 10/group). Data are means, with standard errors represented by vertical bars. The results of statistical analysis by repeated-measures ANOVA with Bonferroni's post hoc correction are described in online Supplementary Table S8.

on lipoprotein size and concentration of consuming a meal containing CSO was equivalent to consuming a meal containing BFO. Moreover, there were no changes in lipoprotein size or concentration that would indicate a potentially harmful effect of consuming CSO.

Consuming a test meal has been associated with an increase in the concentrations in blood of specific inflammatory markers, in particular TNF $\alpha$, IL-6, ICAM-1 and IL-10 ${ }^{(26,38)}$. This inflammatory response has been suggested to be due to the lipid component of a meal, possibly reflecting the level of lipid peroxidation $^{(39,40)}$, although the underlying mechanism and the consequences for health are uncertain. The present findings in the younger age group showed that consuming the test meal induced an increase in the concentrations of TNF $\alpha$, IL- 6 and IL-10, but not sICAM-1 which was consistently below the detection limit of the assay. However, the magnitude of the change in the concentrations of these inflammatory markers did not differ between meals containing different test oils. This suggests that the postprandial inflammatory response that is induced by a meal containing CSO was no greater than a meal containing BFO.

There was no effect of the sex of the participants on any of the outcomes that were measured, which implies that the present findings may be of general relevance to the population. However, the baseline and postprandial (iAUC) EPA and DHA concentrations in plasma TAG and PC were greater in older participants than in the younger age group. This is in agreement with previous findings that showed EPA and DHA incorporation into plasma PC following 12 weeks dietary supplementation with fish oil was greater in men aged 53-70 years than those aged 18-42 years $^{(41)}$. This has been suggested to be due to slower turnover of EPA and DHA in plasma in older compared with younger participants $^{(41)}$. By contrast, there was no significant effect of age on the iAUC of EPA and DHA in plasma NEFA. One possible interpretation is that entrapment of EPA and DHA by tissues may be greater in older compared with younger participants. This suggestion is supported by the observation that the proportions of $22: 5 n-3$ and DHA in adipose tissue increase with age 
in men and women consuming their habitual diets ${ }^{(42)}$ and by the present observation that baseline EPA and DHA concentration in plasma NEFA was higher in older compared with younger participants.

These findings show that, despite differences between test oils in fatty acid composition and the positional distribution of EPA and $\mathrm{DHA}^{(19,32)}$, the postprandial metabolism of these fatty acids when consumed as CSO in an amount comparable with the UK recommended intake for $\mathrm{EPA}+\mathrm{DHA}^{(4)}$ was equivalent that to when consumed as BFO. Hence, the present findings are of direct relevance to current UK and other nutritional guidelines. Since humans require an adequate supply of dietary EPA and DHA for health, one important implication of these findings is that they provide direct evidence to support the view that consuming this oil from transgenic $C$. sativa could provide a sustainable, scalable and apparently safe solution to meeting global demands for EPA and DHA. If so, a further implication is that oils containing EPA and DHA from transgenic plants could reduce demands on limited marine resources and the negative effects of specific restrictive dietary choices and concerns about environmental pollutants on EPA and DHA status.

\section{Supplementary material}

For supplementary materials referred to in this article, please visit https://doi.org/10.1017/S0007114519000825

\section{Acknowledgement}

The authors wish to thank the people who participated in this study for their time and commitment.

This work was supported by grants from the Biotechnology and Biological Sciences Research Council BB/N014081/1 and $\mathrm{BB} / \mathrm{N} 01412 \mathrm{X} / 1$.

G. C. B. has received research funding from Nestle, Abbott Nutrition and Danone. He has served as a member of the Scientific Advisory Board of BASF and is a member of the BASF Asia-Pacific Grant Award Panel. P. C. C. acts as a consultant to BASF AS, Smartfish, DSM, Danone and Fresenius-Kabi. J. A. N. has provided ad hoc consultancy services to BASF.

G. C. B., P. C. C., E. A. M. and J. A. N. designed the study. A. L. W. carried out the dietary intervention and the laboratory analysis. O. S. designed the genetic construct used to engineer C. sativa, L. H. was responsible for transformation, selection and husbandry of the transgenic plants. G. C. B. analysed the data and wrote the first draft of the manuscript. All authors contributed to the final version of the manuscript.

The authors declare that they have no conflicts of interest with the research reported in this article.

\section{References}

1. Lauritzen L, Brambilla P, Mazzocchi A, et al. (2016) DHA effects in brain development and function. Nutrients $\mathbf{8}$, E6.

2. Calder PC (2015) Functional roles of fatty acids and their effects on human health. JPEN J Parenter Enteral Nutr 39, 18S-32S.
3. Kuratko C \& Salem N Jr (2013) Standards for preventing and treating omega-3 fatty acid deficiency. In The Omega-3 Fatty Acid Deficiency Syndrome: Opportunity for Disease Prevention, pp. 399-420 [R McNamara, editor]. Hauppauge, NY: Nova Science Publishers.

4. Scientific Advisory Committee on Nutrition (2006) Advice on Fish Consumption: Benefits and Risks. London: TSO.

5. Givens DI \& Gibbs RA (2006) Very long chain $n$-3 polyunsaturated fatty acids in the food chain in the UK and the potential of animal-derived foods to increase intake. Nutr Bull 31, 104-110.

6. Givens DI \& Gibbs RA (2008) Current intakes of EPA and DHA in European populations and the potential of animal-derived foods to increase them. Proc Nutr Soc 67, 273-280.

7. Rosell MS, Lloyd-Wright Z, Appleby PN, et al. (2005) Longchain $n-3$ polyunsaturated fatty acids in plasma in British meateating, vegetarian, and vegan men. Am J Clin Nutr 82, 327-334.

8. Burdge GC, Tan SY \& Henry CJ (2017) Long-chain $n$-3 PUFA in vegetarian women: a metabolic perspective. J Nutr Sci $\mathbf{6}$, e58.

9. Salem N Jr \& Eggersdorfer M (2015) Is the world supply of omega-3 fatty acids adequate for optimal human nutrition? Curr Opin Clin Nutr Metab Care 18, 147-154.

10. Baker EJ, Miles EA, Burdge GC, et al. (2016) Metabolism and functional effects of plant-derived omega-3 fatty acids in humans. Prog Lipid Res 64, 30-56.

11. Burdge G (2004) $\alpha$-Linolenic acid metabolism in men and women: nutritional and biological implications. Curr Opin Clin Nutr Metab Care 7, 137-144.

12. Burdge GC, Wright P, Jones AE, et al. (2000) A method for separation of phosphatidylcholine, triacylglycerol, non-esterified fatty acids and cholesterol esters from plasma by solid-phase extraction. Br J Nutr 84, 781-787.

13. Burdge GC \& Wootton SA (2002) Conversion of $\alpha$-linolenic acid to eicosapentaenoic, docosapentaenoic and docosahexaenoic acids in young women. Br J Nutr $\mathbf{8 8}, 411-420$.

14. Lohner S, Fekete K, Marosvolgyi T, et al. (2013) Gender differences in the long-chain polyunsaturated fatty acid status: systematic review of 51 publications. Ann Nutr Metab 62, 98-112.

15. Burdge GC, Jones AE \& Wootton SA (2002) Eicosapentaenoic and docosapentaenoic acids are the principal products of $\alpha$-linolenic acid metabolism in young men. Br J Nutr $\mathbf{8 8}$, 355-363.

16. Kwantas JMG \& Grundman O (2015) A brief review of krill oil history, research, and the commercial market. J Diet Suppl $\mathbf{1 2}$, 23-35.

17. Salem N Jr \& Kuratko CN (2014) A reexamination of krill oil bioavailability studies. Lipids Health Dis 13, 137.

18. Kraic J, Mihalik D, Klcova L, et al. (2018) Progress in the genetic engineering of cereals to produce essential polyunsaturated fatty acids. J Biotechnol 284, 115-122.

19. Ruiz-Lopez N, Haslam RP, Napier JA, et al. (2014) Successful high-level accumulation of fish oil omega-3 long-chain polyunsaturated fatty acids in a transgenic oilseed crop. Plant J 77, 198-208.

20. Petrie JR, Shrestha P, Zhou XR, et al. (2012) Metabolic engineering plant seeds with fish oil-like levels of DHA. PLOS ONE $\mathbf{7}$, e49165.

21. Napier JA, Usher S, Haslam RP, et al. (2015) Transgenic plants as a sustainable, terrestrial source of fish oils. Eur J Lipid Sci Technol 117, 1317-1324.

22. Tejera N, Vauzour D, Betancor MB, et al. (2016) A transgenic Camelina sativa seed oil effectively replaces fish oil as a dietary source of eicosapentaenoic acid in mice. J Nutr 146, 227-235.

23. Betancor MB, Sprague M, Usher S, et al. (2015) A nutritionallyenhanced oil from transgenic Camelina sativa effectively replaces fish oil as a source of eicosapentaenoic acid for fish. Sci Rep 5, 8104. 
24. James MJ, Ursin VM \& Cleland LG (2003) Metabolism of stearidonic acid in human subjects: comparison with the metabolism of other $n$-3 fatty acids. Am J Clin Nutr 77, 1140-1145.

25. Burdge GC, Powell J, Dadd T, et al. (2009) Acute consumption of fish oil improves postprandial VLDL profiles in healthy men aged 50-65 years. Br J Nutr 102, 160-165.

26. Burdge GC \& Calder PC (2005) Plasma cytokine response during the postprandial period: a potential causal process in vascular disease? Br J Nutr 93, 3-9.

27. Burdge GC, Powell J \& Calder PC (2006) Lack of effect of meal fatty acid composition on postprandial lipid, glucose and insulin responses in men and women aged 50-65 years consuming their habitual diets. Br J Nutr 96, 489-500.

28. West AL, Burdge GC \& Calder PC (2016) Lipid structure does not modify incorporation of EPA and DHA into blood lipids in healthy adults: a randomised-controlled trial. $\mathrm{Br} J \mathrm{Nutr}$ 116, 788-797.

29. Browning LM, Walker CG, Mander AP, et al. (2012) Incorporation of eicosapentaenoic and docosahexaenoic acids into lipid pools when given as supplements providing doses equivalent to typical intakes of oily fish. Am J Clin Nutr 96, 748-758.

30. Schuchardt JP, Schneider I, Meyer H, et al. (2011) Incorporation of EPA and DHA into plasma phospholipids in response to different omega-3 fatty acid formulations - a comparative bioavailability study of fish oil vs. krill oil. Lipids Health Dis 10, 145.

31. Nordoy A, Barstad L, Connor WE, et al. (1991) Absorption of the $n-3$ eicosapentaenoic and docosahexaenoic acids as ethyl esters and triglycerides by humans. Am J Clin Nutr 53, $1185-1190$

32. Bottino NR (1971) The composition of marine-oil triglycerides as determined by silver ion-thin-layer chromatography. J Lipid Res 12, 24-30.

33. Nilsson-Ehle P, Egelrud T, Belfrage $\mathrm{P}$, et al. (1973) Positional specificity of purified milk lipoprotein lipase. J Biol Chem 248, 6734-6737.
34. Yang LY \& Kuksis A (1991) Apparent convergence (at 2-monoacylglycerol level) of phosphatidic acid and 2-monoacylglycerol pathways of synthesis of chylomicron triacylglycerols. J Lipid Res 32, 1173-1186.

35. Evans K, Burdge GC, Wootton SA, et al. (2002) Regulation of dietary fatty acid entrapment in subcutaneous adipose tissue and skeletal muscle. Diabetes 51, 2684-2690.

36. Burdge GC, Sala-Vila A, West AL, et al. (2007) The effect of altering the $20: 5 n-3$ and $22: 6 n-3$ content of a meal on the postprandial incorporation of $n-3$ polyunsaturated fatty acids into plasma triacylglycerol and non-esterified fatty acids in humans. Prostaglandins Leukot Essent Fatty Acids 77, 59-65.

37. Heath RB, Karpe F, Milne RW, et al. (2003) Selective partitioning of dietary fatty acids into the VLDL TG pool in the early postprandial period. J Lipid Res 44, 2065-2072.

38. Telle-Hansen VH, Christensen JJ, Ulven SM, et al. (2017) Does dietary fat affect inflammatory markers in overweight and obese individuals? - a review of randomized controlled trials from 2010 to 2016. Genes Nutr 12, 26.

39. Esposito K, Nappo F, Giugliano F, et al. (2003) Effect of dietary antioxidants on postprandial endothelial dysfunction induced by a high-fat meal in healthy subjects. Am J Clin Nutr 77, 139-143.

40. Nappo F, Esposito K, Cioffi M, et al. (2002) Postprandial endothelial activation in healthy subjects and in type 2 diabetic patients: role of fat and carbohydrate meals. J Am Coll Cardiol 39, $1145-1150$.

41. Rees D, Miles EA, Banerjee T, et al. (2006) Dose-related effects of eicosapentaenoic acid on innate immune function in healthy humans: a comparison of young and older men. Am J Clin Nutr 83, 331-342.

42. Bolton-Smith C, Woodward M \& Tavendale R (1997) Evidence for age-related differences in the fatty acid composition of human adipose tissue, independent of diet. Eur J Clin Nutr 51, 619-624. 